\title{
ALFABETIZAÇÃO E LETRAMENTO DE ESTUDANTES COM SURDEZ: ANÁLISE DAS PROVAS DE AVALIAÇÃO DOS PROCESSOS DE LEITURA E SUAS CONTRIBUIÇÕES
}

Érica Farias Silva, Tamiris Santana da Silva, Danielle Aparecida do Nascimento dos Santos, Sandra Silva Lustosa Dearo

Universidade do Oeste Paulista - UNOESTE, Curso de Fonoaudiologia, Presidente Prudente, SP. E-mail: ericafariassilva@hotmail.com, tamiris-santana1@hotmail.com, danielle@unoeste.br e slustosa@unoeste.br.

\section{RESUMO}

A importância do letramento (atividade da tecnologia da escrita) na alfabetização de estudantes surdos envolve a possibilidade de ler e escrever para cumprir objetivos diversos como informar, interagir com o outro, contar uma história, ampliar conhecimentos, orientar-se, divertir, entre outros. Nessa perspectiva, o objetivo da pesquisa foi analisar o material PROLEC - PROVAS DE AVALIACAO DOS PROCESSOS DE LEITURA e suas contribuições para o letramento de estudantes com surdez. A abordagem da pesquisa é qualitativa. A análise foi realizada mediante critérios como a organização e classificação do material. As categorias analíticas foram geradas a partir dos eixos: contextualização do PROLEC, Estudos sobre o PROLEC, Descrição das provas e normas de aplicação. Os resultados apontam que é possível usar o PROLEC para a educação escolar do aluno surdo. Conclui-se que o material pode contribuir no contexto da inclusão de estudantes surdos em uma abordagem de seus processos de leitura e escrita.

Palavras-chave: Alfabetização. Letramento. Avaliação. Surdez. Inclusão.

\section{LITERACY AND LETTERING OF DEAF STUDENTS: ANALYSIS OF EVIDENCE OF EVALUATION OF READING PROCESSES AND THEIR CONTRIBUTIONS}

\begin{abstract}
The importance of literacy in literacy of deaf students involves the ability to read and write to accomplish diverse goals such as informing, interacting with others, telling a story, expanding knowledge, orienting oneself, having fun, among others. In this perspective, the objective of the research was to analyze the PROLEC - ASSESSMENT PROOF OF THE READING PROCESSES and their contributions to the literacy of students with deafness. The research approach is qualitative. The analysis was performed using criteria such as the organization and classification of the material. The analytical categories were generated from the axes: contextualization of PROLEC, Studies on PROLEC, description of the tests and application standards. The results indicate that it is possible to use PROLEC for the deaf student's school education. It is concluded that the material can contribute in the context of the inclusion of deaf students in an approach to their reading and writing processes.
\end{abstract}

Keyword: Literacy. Literature. Testing. Deafness. Inclusion. 


\section{INTRODUÇÃO}

Letramento é o estado que assume aquele que sabe ler e escrever, para ela o fenômeno do letramento tem uma forte relação com o alfabetismo, mas não se confunde com esse processo, pois a alfabetização é o processo pelo qual se adquire o domínio de um código e das técnicas para utilizá-lo no momento em que lemos e escrevemos (1). Letramento é, portanto, a atividade efetiva da tecnologia da escrita, a qual envolve a possibilidade de ler e escrever para cumprir objetivos diversos: informar, interagir com o outro, fazer uma declaração, contar uma história, ampliar conhecimentos, orientar-se, divertir, entre outros.

É por meio do contexto familiar que a criança tem seus primeiros contatos com a linguagem escrita, estabelece seus primeiros significados. Se desde cedo uma criança convive com materiais de leitura, tais como: livros, jornais e revistas, se ouve histórias e observa as pessoas lendo e escrevendo e manipula lápis, borracha, papel, ao ingressar na escola achará tudo muito natural e lógico, já que será uma continuidade daquilo que já vivenciava em casa (2). O acesso a diferentes materiais de leitura em casa, facilita a construção de hipóteses sobre a escrita e a percepção das diferenças entre esta e a fala (3).

No caso o letramento de estudantes surdos, há uma considerável parcela que não teve acesso à língua de sinais, quer seja por motivo de isolamento social, quer seja pelo fato de a família optar por uma escola que não utilize essa língua, o que causa, além de defasagens escolares, dificuldade e/ou impedimento quanto à inserção dessas pessoas no mercado de trabalho. Cabe esclarecer que, ainda hoje no Brasil, são poucas as escolas que oferecem uma proposta bilíngue, na qual a língua de sinais é a principal língua utilizada na escola, a maioria das escolas brasileiras ainda utiliza somente a Língua Portuguesa (3).

A educação bilíngue é essencial para instrumentalizar o surdo para torna-se um sujeito letrado, no entanto, essa perspectiva ainda encontra-se envolta em muitas dúvidas e questionamentos por parte dos professores, que por um lado não são proficientes na primeira língua do surdo, pois não tiveram acesso à formação específica para tal.

O surdo precisa desenvolver uma língua efetiva, e, para que isso ocorra, é necessário que as experiências escolares oferecidas a ele privilegiem não apenas a língua de sinais, mas também os aspectos discursivos da escrita, já que esses são fundamentais para que qualquer sujeito, surdo ou ouvinte, se constitua como falante, leitor e escritor, realizando um trabalho que proporcione a reflexão sobre o uso da linguagem oral, escrita e da língua de sinais.

Levando em consideração essa realidade e também as dificuldades que as crianças surdas apresentam com a linguagem escrita, o artigo versa a pesquisa de iniciação científica desenvolvida no âmbito do Curso de Fonoaudiologia, orientado pelos objetivos: Geral: analisar o material PROLEC PROVAS DE AVALIACAO DOS PROCESSOS DE LEITURA e suas contribuições para o letramento de estudantes com surdez; Específicos: refletir sobre o desenvolvimento de uma educação que eleve as potencialidades, as habilidades e competências das pessoas e da importância do letramento como um instrumento de formação cidadã; avaliar como as práticas de leitura e escrita utilizando o PROLEC podem ser usadas no ambiente escolar para o ensino de Língua Portuguesa como segunda língua e consequente letramento do indivíduo com surdez.

Nesse sentido, serão apresentados os aspectos que caracterizam as condições de letramento em indivíduos com surdez mediante a perspectiva de análise de material para a aplicação de provas de leitura. 


\section{METODOLOGIA}

O estudo é qualitativo de natureza exploratória. De acordo com Denzin e Lincoln (2006), a pesquisa qualitativa é centrada em uma abordagem interpretativa, em que o pesquisador estuda significados e fenômenos, buscando entender a perspectiva muito mais em termos de processo do que de produto. (4)

A natureza exploratória faz com que o pesquisador busque familiarizar-se com um assunto ainda pouco conhecido ou explorado. Nesse sentido, optou-se por revisão de literatura e análise documental. Foram consultadas as bases de dados Scielo e Lilac, tendo como base as produções dos últimos 10 anos, usando os descritores: surdez, alfabetização e letramento, avaliação e PROLEC.

Optou-se por realizar uma análise sobre a aplicabilidade do PROLEC, pois consiste em explorar os processos que interferem na leitura, considerando o processamento periférico e central. É estruturado a partir do referencial teórico e orientações aos aplicadores. As provas derivam de um modelo bem fundamentado sobre o funcionamento do sistema de leitura (Dupla Rota) (5).

Para compor a análise detalhada do material, foram estruturadas categorias vinculadas aos eixos significante e significado. Esses eixos foram organizados enquanto contextualização do PROLEC, estudos sobre o PROLEC, descrição das provas e normas para aplicação.

Com isso, foi elaborada uma análise sobre as estratégias que cada estudante pode utilizar na leitura de um texto, bem como os mecanismos que não estão funcionando adequadamente para que se realize uma boa leitura, sendo enfocados aspectos referentes à educação escolar do aluno surdo no contexto da inclusão e seu processo de leitura e escrita.

\section{RESULTADOS}

O conhecimento dos mecanismos envolvidos no processo de leitura e compreensão de um texto escrito permite melhor compreensão do funcionamento da mente humana e possibilita também o entendimento sobre o que acontece com o escolar que apresenta dificuldades na leitura, nesse sentido, contextualizamos o material analisado.

Para explicar o processo de aprendizagem da leitura no PROLEC foi utilizado o modelo da Dupla Rota. Tal modelo define que a leitura ocorre por meio de um processo que envolve a mediação fonológica (rota fonológica) ou pelo processo visual direto (rota lexical). A leitura pela rota fonológica depende do conhecimento das regras de conversão entre grafema e fonema, para que a construção da pronúncia da palavra possa ser efetuada.

A avaliação da leitura tem se concentrado na precisão, na decodificação e na memória para recordar textos, mas sem avaliar os processos que interferem na leitura. (5) Pretende-se avaliar os diferentes processos e subprocessos que interferem na leitura, para identificar os casos de dificuldades em sua aprendizagem. Assim, estas provas objetivam disponibilizar á comunidade cientifica, clínica e escolar um instrumento de avaliação com base em critérios e normas de desenvolvimento de leitura, para o estabelecimento do perfil de leitura de escolares.

Por meio do PROLEC, é possível compreender as dificuldades de leitura, bem como ter auxilio na análise do diagnóstico dos transtornos de aprendizagem. São obtidas informações sobre as estratégias que cada escolar utiliza na leitura de um texto, bem como os mecanismos que não estão funcionando adequadamente para que se realize uma boa leitura, o que é de extrema importância na hora de buscar seu aperfeiçoamento ou recuperação.

O instrumento Provas de Avaliação dos Processos de Leitura - PROLEC foi adaptado para a realidade brasileira, com a intenção de fornecer aos pesquisadores e profissionais da área de saúde e da educação, um instrumento de avaliação com base em critérios e normas de desenvolvimento de leitura, pois por meio do uso deste instrumento será possível avaliar os diferentes processos e 
subprocessos que interferem na leitura, e assim, identificar os casos de dificuldades ou transtornos de aprendizagem e quais os processos responsáveis por essas dificuldades.

Foi desenvolvido por Fernando Cuetos, Bianca Rodriguez, Elvira Ruano, em 1996, no Departamento de Psicologia da Universidade de Oviedo, como fruto de um projeto de investigação financiado pelo CIDE, sendo sua última versão publicada em 2004. Orginalmente, as provas foram aplicadas individualmente em uma amostra de escolares dos quatro primeiros anos do ensino fundamental, pertencentes aos três principais tipos de escolas existentes na Espanha, escola pública urbana e rural e escola particular urbana, foram avaliados 403 escolares.

$\mathrm{Na}$ análise de variância realizada não foi encontrada diferença entre as escolas, muito menos entre os gêneros. Foram encontradas diferenças entre os níveis escolares, como os autores esperavam, já que à medida que o ano escolar aumenta a execução de leitura torna mais eficaz. Para validar o procedimento os autores optaram pelo critério externo, a opinião do professor, solicitando que pontuassem a capacidade de leitura de cada um de seus alunos, em uma escala de 0 a 10 . Essas pontuações são correlacionadas com as obtidas em cada uma das provas e com a pontuação total de cada escolar e todas foram significativas. As características psicométricas da adaptação brasileira, os participantes do estudo analisado, foram selecionados dos três principais tipos de escolas existentes no Brasil, escola municipal, escola particular e escola rural. Participaram 401 escolares do ensino fundamental de uma Cidade do interior do estado de São Paulo.

No estudo realizado com alunos surdos nas Ilhas Canárias matriculados em 34 escolas no sistema de ensino durante o ano de 2002-2003, composto por 93 alunos surdos (46 do sexo feminino e 47 do sexo masculino), com idades entre 9 anos e 5 meses a 20 anos e 4 meses, com perda auditiva neurossensorial pré-lingual, sem qualquer outra deficiência associada, 95,4\% tinha surdez profunda bilateral. Primeiramente foi utilizado o subteste do PROLEC de Compreensão de sentenças (5). 0 objetivo deste subteste é verificar se o aluno pode extrair o significado de frases simples, para o qual há recursos de memória especiais são solicitados. O resultado obteve a média total do grupo de surdos de 7,99\%, o que indica que todo o grupo de surdos deram respostas corretas a $66,6 \%$ das perguntas. Esta média é mais baixa do que a média dos alunos ouvintes, de acordo com o PROLEC, média de 10,1\% para o primeiro ano do ensino primário e 11,42\% para o segundo ano.

Seguidamente foi utilizado o outro subteste, a compreensão do texto, no qual o objetivo era verificar se o aluno pode extrair o significado dos textos e integrá-lo com o conhecimento anterior. 0 resultado obtido foi à média total do grupo de surdos de 6,99\%, o que significa que o grupo de surdos respondeu corretamente $43,7 \%$ das perguntas. Este valor médio é menor do que o valor médio obtido pelos alunos auditivos, de acordo com o PROLEC a média de 8,0\% para o primeiro ano do ensino primário, $11,6 \%$ para o segundo ano, $12,3 \%$ para o terceiro ano, 13,5\% para o quarto ano. Os resultados do estudo demostraram que o nível de leitura dos surdos é semelhante ou mais baixo do que das pessoas ouvintes. 


\section{DISCUSSÃO}

No ano de 2001-2002 participaram de outro estudo 17 estudantes com surdez profunda, prélingual inscritos na escola Hispano-americano da Palavra de Madrid com faixa etária de 4 a 12 anos (7). A medida foi feito habilidades de leitura através da leitura de palavras de teste PROLEC. O segundo objetivo deste estudo foi testar se o ensino explícito da consciência fonológica na aprendizagem precoce das crianças facilita a leitura na primeira série. Nas três primeiras avaliações (correspondente a pré-primária) nenhum estudante conseguiu ler, demonstrando que as crianças não receberam ensino explícito de leitura, porém na quarta avaliação, tiveram uma pontuação média de 19 palavras lidas corretamente e na quinta eles passaram a ler uma média de 24 palavras no ensino primária, mostrando que houve uma melhoria na pontuação na leitura de palavras.

A segunda questão abordada neste estudo foi avaliar se o desenvolvimento da consciência fonológica permite que as crianças surdas aprendam a ler mais facilmente do que as crianças surdas que esta consciência não foi explicitamente desenvolvida. Os resultados obtidos neste estudo mostram diferenças substanciais entre essas crianças, ou seja, aqueles que não tinham recebido instrução explícita antes de iniciar a aprendizagem formal da língua escrita. Portanto verificaram que as habilidades metafonológicas variavam de acordo com o nível de educação e que havia uma relação clara com habilidades de leitura, avaliadas pelo PROLEC.

\section{DESCRIÇÃO DAS PROVAS}

As provas se agrupam em quatro blocos, correspondentes aos quatro processos que intervém na compreensão do material escrito. Começando pela identificação de letras, destinado a medir a capacidade dos escolares para identificar as letras e seus respectivos sons, dividido em nome ou som. Para ler é imprescindível conhecer todas as letras, por isso o objetivo dessa tarefa é averiguar se o escolar conhece as mesmas ou se apresenta problema com algumas delas, a pontuação nesta tarefa vai de 0 a 20. E igual-diferente em escolares e pseudopalavras, no qual o objetivo desta prova é comprovar se o escolar é capaz de realizar esta tarefa, utilizando pares de estímulos que somente se diferenciam em uma letra, exigindo grande atenção visual. São apresentados pares de palavras ou pseudopalavras iguais, ou com uma letra trocada, para que indique se são iguais ou diferentes, a pontuação vai de 0 a 20.

O processo léxico formado pela decisão léxica, no qual trata de medir o nível de representações ortográficas que o escolar possui, com o objetivo de comprovar se o sujeito é capaz de reconhecer as palavras, são apresentadas palavras e pseudopalavras para que os escolares indiquem se a palavra é real ou inventada em 30 itens apresentados. Na leitura de palavras o paciente tem que ler em voz alta uma lista de 30 palavras formadas por silabas de diferentes complexidades, o resultado é comparado com a prova anterior. Na leitura de Pseudopalavras, juntamente com a leitura de palavras, esta prova tem como objetivo comparar o desenvolvimento das rotas de reconhecimento de palavras. A tarefa consiste na leitura de uma lista de 30 pseudopalavras formadas por silabas de diferentes complexidades silábicas, como apresentadas na prova anterior.

$\mathrm{Na}$ leitura de palavras e pseudopalavras, o objetivo de analisar o grau de desenvolvimento que - escolar alcançou com as rotas de leitura, é utilizado palavras e pseudopalavras mescladas e pertencentes a seis categorias (palavras frequentes curtas e longas, palavras não frequentes curtas e longas e pseudopalavras curtas e longas). Quanto maior a diferença entre os resultados das palavras de alta frequência e as de baixa frequência, e entre estas as pseudopalavras, maior será o uso da rota léxica.

O processo sintático consiste na estrutura gramatical, conhece a capacidade que o escolar possui em atribuir os pares sintáticos, as palavras que compõem uma oração. A finalidade desta prova 
é comprovar a dificuldade que se pode produzir ao utilizar distintas estruturas sintáticas, sendo exploradas três tipos de estruturas: voz ativa, passiva e complemento focado. A prova consta de 15 itens e um exemplo, composto de um desenho e três orações. Os sinais de pontuação tem como objetivo investigar se o escolar é capaz de realizar as pausas e entonações que indica os sinais de pontuação.

O processo semântico consiste na compreensão de orações, o objetivo desta prova é avaliar se o escolar é capaz de extrair o significado de simples orações que são apresentadas. A prova é formada por doze ações que expressam ordens simples que o leitor deve executar. E na compreensão de textos esta prova é formada por quatro pequenos textos e tem como objetivo investigar se o escolar é capaz de extrair o significado e integrá-lo aos seus conhecimentos. Os textos foram extraídos da coleção intitulada "Português: uma proposta para o letramento" publicados pela Editora Moderna (1).

\section{CONCLUSÃO}

É inegável reconhecer a relevância de pesquisas sobre educação bilíngue, uma vez que o ato de ler e escrever é importante para a vida, pois, além de ser recurso de comunicação possibilita o acesso à informação e amplia a capacidade de compreensão para atuação de forma plena na sociedade.

A análise do material e das pesquisas que utilizaram o PROLEC para o processo de letramento de indivíduos surdos revela que pode ser possível avaliar os diferentes processos e subprocessos que interferem na leitura, e assim, identificar os casos de dificuldades ou transtornos de aprendizagem e quais os processos responsáveis por essas dificuldades, no caso das crianças surdas. Além de permitir que sejam obtidas informações sobre as estratégias que cada escolar utiliza na leitura de um texto, bem como os mecanismos que não estão funcionando adequadamente para que se realize uma boa leitura.

A partir da pesquisa, foi possível refletir sobre o desenvolvimento de uma educação que eleve as potencialidades, as habilidades e competências das pessoas e da importância do letramento como um instrumento de formação cidadã.

\section{REFERÊNCIAS}

1. Soares M. Letramento e Escolarização. Letramento no Brasil. São Paulo: Global, 2004. 287 p.

2. Cagliari LC. Alfabetização e Lingüística. São Paulo: Scipione, 1995.

3. Guarinello AC. et al. Surdez e letramento: Pesquisa com surdos universitários de Curitiba e Florianópolis. Revista Brasileira de educação especial, Marília, v.15, n.1, p.99-120, jan./abr. 2009.

4. Denzin NK, Lincoln Y. A disciplina e a pratica da pesquisa qualitativa. Planejamento da pesquisa qualitativa: teorias e abordagens. 2 ed. Porto Alegre: Artmed, 2006.

5. Capellini SA, Oliveira AM, Cuetos F. Provas de avaliação dos processos de leitura. Casa do Psicólogo. 2o edição - Revisada e ampliada. São Paulo, 2012.

6. Monreal ST, Hernández RS. Reading levels of Spanish deaf students. American annals of the deaf. v.150, n. 4, Universidad de Las Palmas de Gran Canária, february, 2005. 
7. Dominguez $A B$, Rodriguez PR, Alonso B. Cómo facilitar el aprendizaje de la lectura de niños sordos. Importancia de las habilidades fonológicas. Revista de Educación, p. 353-375, sep-dic, 2011. 